\title{
ASSESSING Sexual HEALTH Knowledge in an Urban Female Population, to educate WITH A DIGITAL CURRICULUM
}

\author{
Lucki Word, MA, Melanie Hanna-Johnson, MD, MHSA, Anil N. F. Aranha and PhD
}

Publisher's Note: MDPI stays neutral with regard to jurisdictional claims in published maps and institutional affiliations.

\section{(c) (7)}

Copyright: $\odot 2020$ by the authors. Submitted for possible open access publication under the terms and conditions of the Creative Commons Attribution (CC BY) license (http://creativecommons.org/licenses /by/4.0/).

\footnotetext{
${ }^{1}$ Departments of Internal Medicine, Diversity and Inclusion, and Medical Education, Wayne State University School of Medicine, Detroit, MI 48201, U.S.A.
}

PURPOSE: Obtaining accurate facts related to sexual health can be a challenging task, due to variation in available resources. Search engines and social media outlets offer effortless communication about virtually any topic of interest. Aptitude in basic reproductive health information is essential, especially in female populations. Urban female populations often contain numerous members of marginalized groups. Our study aims to evaluate sexual health knowledge (SHK) in an urban female population, and determine how the prevalence of high-tech communications, as well as face to face connections, influences SHK values.

METHODS: A 50 item survey, capturing sociodemographics, extent and form of social interactions (electronic and in-person), and SHK, was created to evaluate correlates of sexual and reproductive health. Of the 50-item survey, 18 questions were knowledgebased inquiries, with one correct response. One point was administered for correct answers, for a maximum score of 18 . The survey was administered to agreeing adult patients in two ambulatory, urban primary care settings. Data was coded and analyzed using IBMSPSS. Statistical analysis included: Pearson correlation $(r), t$ and Chi-squared tests. Statistical significance was established at $\mathrm{p}<0.05$.

RESULTS: Of 287 total female patients, $85.7 \%$ African-American, $66.2 \%$ having incomes $<\$ 50,000$ USD; with values for mean age of $55.3 \pm 14.8$, years of schooling of $14.2 \pm$ 2.5. and $10.4 \pm 3.4$ for SHK, on a scale of $0-18$. SHK deficits were indicated among the group. Number of technological communications $(\mathrm{p}<0.001)$ and sum of weekly face to face exchanges $(p>0.05)$, both were positively correlated with SHK score.

CONCUSION: Our data exposes gaps of SHK, due to frequency and form of communications. Further research efforts, to enhance the equity of delivering a digital SHK curriculum, are in progress. 